\title{
Obesity in the fire service: An inside look at the perceptions of firefighters towards obesity and other health issues
}

Matthew Bucala ( $\sim$ mattbucala@gmail.com )

University of Massachusetts Boston https://orcid.org/0000-0003-2251-9842

Elizabeth Sweet

University of Massachusetts Boston

\section{Research article}

Keywords: Obesity, fire service, diet, exercise, sleep, firefighter, cancer, cardiovascular, culture

Posted Date: October 4th, 2019

DOI: https://doi.org/10.21203/rs.2.15518/v1

License: (c) (i) This work is licensed under a Creative Commons Attribution 4.0 International License.

Read Full License 


\section{Abstract}

Background Despite being an extremely physically demanding job, there exists a high prevalence of obesity for members of the fire service nationally based on recent studies. The fire service has a unique culture and environment that likely influences behaviors and attitudes among the members, and in turn impacts their health.

Objectives Based on previous research we hypothesized that cultural and structural aspects of the fire service contribute to the rise in obesity among its members. The primary aims of this research project were: (1) to determine the current extent, or prevalence, of obesity among members of a large eastern US fire department ("X Fire Department"), and (2) to elucidate aspects of the physical and cultural environment that may contribute to obesity risk among members (specifically, diet, exercise, and sleep).

Methods This two-phase, mixed-methods study involved conducting qualitative interviews with $(n=17)$ members of the X Fire Department (Phase I) and collecting online questionnaire data $(n=120)$ from a broader department-wide sample of 1,400 active members.

Results The data gathered in Phase II indicated that out of the $(n=120)$ members that participated in the study the average BMI was 29 with approximately $40 \%$ of the respondents falling into the category of obese. The data indicated that while overall diet and exercise has improved in the department in recent years there are still factors impacting the diet, exercise, and sleep levels of the members that contribute to risk for obesity and other adverse health conditions.

Conclusion There are factors in the X Fire Department that are negatively impacting the members' ability to eat, exercise, and sleep properly, which in turn we believe is directly attributable to the high percentage of obesity in our study. Our hope is that this research will highlight the areas that require immediate action and to add to existing research in order to instill in a change in other fire departments nationally.

\section{Introduction}

The lifestyle of firefighters is unique as the members are positioned at stations where they spend 48 hours per week collectively eating, sleeping, and responding to emergencies with their fellow firefighters. The work of a firefighter requires that they be in proper physical shape allowing them to function at an extremely high level for extended periods. However, in many of the busiest stations across the United States responding to incidents can make things such as eating meals, exercising, or getting a sufficient amount of rest difficult. Given the strenuous nature of the fire service, maintaining a level of physical fitness and a healthy weight is not only conducive to being successful during an incident, but it is also paramount in reducing additional health risks such as cardiovascular disease, diabetes, and certain forms of cancer that affect firefighters.

Despite the extremely physical nature of the fire service the members of X Fire Department (this pseudonym will be used throughout to protect confidentiality) and many other departments throughout 
the United States are not subjected to any physical fitness or weight/BMI requirements after being hired and completing their initial training at the fire academy. The National Fire Protection Association offers information and guidelines on how to implement fitness evaluations but does not stipulate that they must be followed (1). Instead, it is up to each member, company officer, or department to prescribe and motivate themselves and the other members to engage in exercise.

Recent studies have found that obesity in the fire service has become a prominent and widespread issue that impacts members at an alarming rate of over $70 \%$ of all firefighters in the United States, which is significantly higher than the $39.8 \%$ obesity rate of the general population $(2,3$, and 4$)$. Researchers have found that the structure of the fire department which includes things such as shift work and responding to emergencies at any given moment can influence the culture, which can then perpetuate certain behaviors leading to negative health outcomes. For example, due to the nature of shift work in the fire department members are often forced to make unhealthy food choices because they are too tired to engage in proper meal preparation (5). Conversely, while there are firefighters negatively impacted by fatigue from incident responses there are also fire stations that receive very few incident responses resulting in frequent sedentary behaviors, which also puts them at increased risk for obesity (6). The infrequency of incident responses throughout a shift can lead to periods of boredom for the members causing them to consume unnecessary calories. Additionally, research has shown that boredom can lead to eating unnecessarily, which in turn can lead to weight gain (7).

Shift work has also been found to contribute to weight gain on average firefighters gain approximately 3.5lbs per year, which compounded throughout their careers can range between 29-85lbs over the span of twenty to thirty years (average career length for a firefighter) (8). Shift work has also been found to increase the risk for diseases such as obesity, hypertension and myocardial infarction $(9,10)$. Additionally, the 24-hour work schedule that the members of the fire department must adhere to causes interrupted sleep or poor sleep quality, which has been found to increase the risk of subclinical multiterritory atherosclerosis (11).

The risk factors firefighters face are further compounded by exposure to extreme heat in conjunction with physical exertion associated with fighting fires as it can cause damage to the cardiovascular system, and damage healthy heart tissue, which then puts members at a greater risk for myocardial infarction (12). One of the leading causes of the line of duty deaths (LODD) (45\%) in the fire service is coronary heart disease $(12,13)$. Additionally, members who are overweight or obese are also at an increased risk for cardiovascular disease and other non-communicable diseases $(13,14)$.

The primary aims of this research project were to determine the current extent, or prevalence, of obesity among X Fire Department members, and to elucidate aspects of the physical and cultural environment that may contribute to obesity risk among members (specifically, diet, exercise, and sleep). To our knowledge, no such study of the factors contributing to obesity risk among members of the X Fire Department has been conducted. This research also contributes to the broader literature on the obesity epidemic in the fire service by expanding both qualitative and quantitative data on the health-related 
environment of fire departments. By employing a mixed-methods design, this study captures a rich understanding of the perceptions and beliefs of fire service members regarding their own health and obesity risk. By focusing on individual, cultural, and structural dimensions of lifestyle and behavior, we seek to provide a comprehensive view of the multiple aspects of fire service that likely impact health. By focusing on what members believe to be the most significant factors in the fire department affecting diet, exercise, and sleep, this research serves as a gateway for developing effective interventions and solutions to improve the health of fire service members. Ultimately, the obesity epidemic within the fire service is a serious concern and poses a significant threat to the members and the citizens they have chosen to serve and protect.

\section{Methods}

\subsection{Study design and recruitment}

The research study was conducted with assistance and oversight provided by members of the Safety, Health, and Wellness Division (SHWD) within the X Fire Department. The study was conducted in two phases: a qualitative interview phase and a quantitative questionnaire phase. Both phases of the study took place between June 2018 and December 2018. Participants for Phase I were recruited by passing out participation flyers to the Captains in charge of the 4 fire stations involved in the study who then left the flyers in the common areas for members to view them. The fire stations selected for Phase I were predetermined by members of the SHW division. Participants for Phase II were recruited by sending out a department-wide email that explained the nature of the study and reinforcing that it was both anonymous and voluntary. All study procedures were reviewed by the SHWD of the fire department and the Institutional Review Board at UMass Boston for the ethical treatment of human subjects and was determined to be exempt since no identifying information was collected from participants.

\subsection{Phase I overview}

Phase I consisted of semi-structured, qualitative interviews with 17 fire service members from 4 different stations. The stations were chosen to represent a range in incident call volume from "busy" $(>3,500$ incident responses per year), "moderate" (between 1,500 and 3,500 incident responses per year), and "slow" ( $<1,500$ incident responses per year), which granted the study the best possible representation of station environments that members are likely to experience.

\subsection{Phase 1 questions and analysis}

Interviews focused on demographics, diet, exercise, sleep, obesity, job performance, potential solutions, and overall health. First, we asked each participant questions targeting socio-demographics (highest education completed, age, rank within the fire service, total years served, years at current station, and the number of other stations assigned). Next, we asked each participant to describe their overall diet and then 
explain whether or not it differed while in the firehouse versus their time at home. We also asked them to describe the "culture" of food or meals in the firehouse, specifically, focusing on the type of foods, and portion sizes. After dietary questions, we asked the participants questions about their experiences with exercise that targeted importance and frequency of exercise both in the firehouse and on their own time. We then asked the members to describe the "culture" of exercise in the department, specifically focusing on the attitudes and beliefs of other members. We transitioned from exercise-related questions into questions targeting the amount and quality of sleep they and other members get. We also asked the participants "do you feel as though obesity is prevalent in the department and if so why?" in order to determine how the members' perceive obesity. Finally, we asked the participants if they received the proper resources from the department to maintain proper health and if instituting a weight and fitness requirement would be beneficial.

Interviews ranged in length from 27 minutes to 41 minutes, and averaged 33 minutes. All interviews were conducted in private room by MB and were digitally recorded and transcribed verbatim. Key themes were identified using the semi-structured interview guide as well as techniques for theme identification outlined by Ryan and Bernard (2003) (15).

\subsection{Phase Il overview}

Phase II consisted of distributing online surveys to the entire department. The construction of the Phase II survey was informed by the interview responses from Phase I and questions were designed to elaborate and follow up on themes from interviews.

\subsection{Phase II questions}

Questionnaire components included socio-demographics (highest education completed, age, rank within the fire service, total years served, and years at current station) several aspects of health and wellness opportunities within the department (food quantity and quality, exercise and fitness options, sleep environments), attitudes towards fitness and lifestyle, and endorsements of potential changes and interventions within the department. Additional questions assessed member health, including selfreported height and weight, subjective assessments of fitness, and a 10-point rating of general health. A total of 126 members participated in Phase Il of the study ( $9 \%$ of the total membership). Descriptive statistics (frequencies, means, and standard deviations) were calculated as appropriate, and t-tests and linear regressions were used to test associations among variables. All statistical analyses were conducted using STATA statistical software.

\section{Results Phase I}

\subsection{Demographics}

Table. 1 Demographics for the participants from Phase I of the study. 


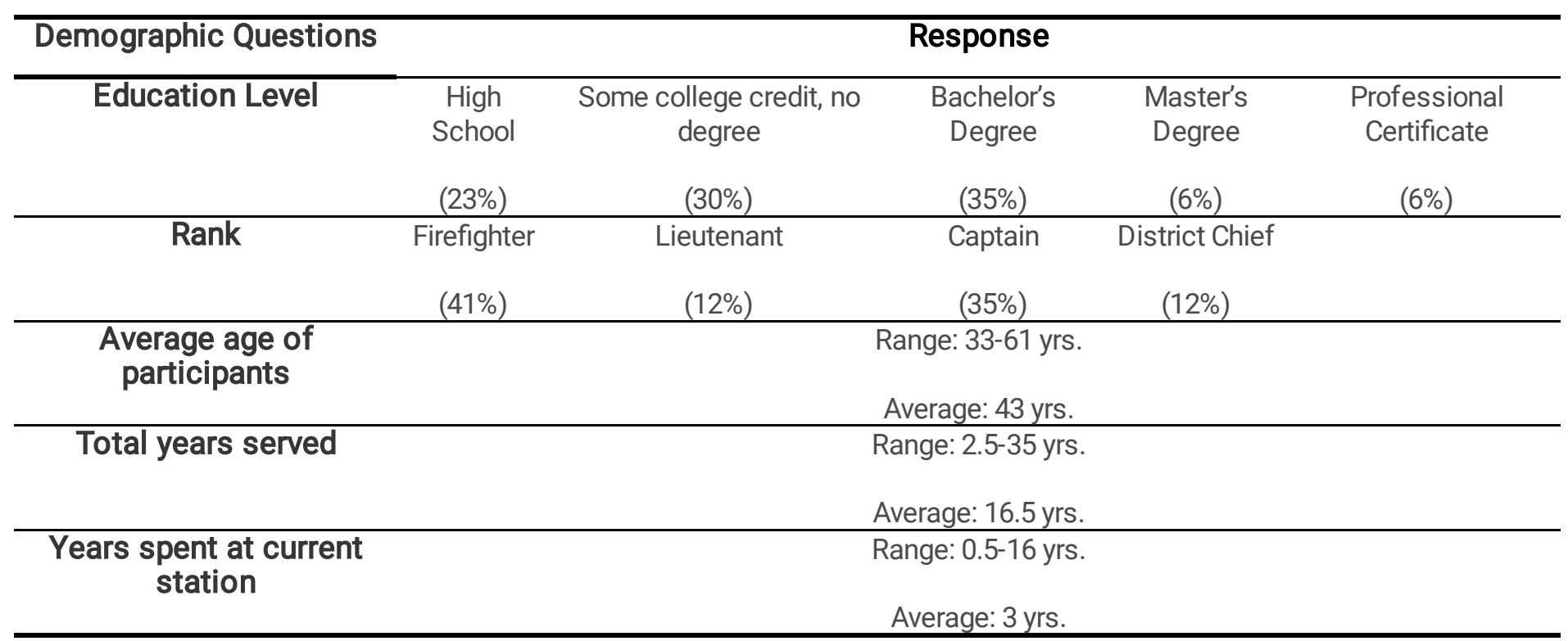

\subsection{Diet-related questions}

In response to diet-related questions, a key theme that emerged related to portion sizes and unhealthy food options. For instance, one member explained that the portion sizes are too large and he said that he often he eats "a little too much for dinner due to the larger portion sizes" (Participant \#4, interview with author, June 2018). Another member noted that "the amount of food they serve for dinner could feed a soup kitchen. Generally, the fire service prepares for seconds and we cook so guys can have seconds" (Participant \#7, interview with author, June 2018).

One member illustrated the nature of diet in the fire department as he explained that

"The culture of food within the fire department, in general, is centered around being very carb heavy as many meals contain things like lasagna, meatloaf, and other very dense meals. Also, the portions for dinner are very large and that most members typically at least go back for seconds during dinner. The portions are so large because you can never be sure exactly how much the members will eat, and you don't ever want to run out of food but if the food is available the members will eat it. Dessert is another major issue as there is always ice cream in the fridge and this is common knowledge among all the members" (Participant \#14, interview with author, July 2018).

\subsection{Exercise-Related Questions}

In response to exercise-related questions almost every participant noted that exercise is an extremely important aspect of staying healthy and is imperative to performing effectively as a firefighter. Additionally, most members noted that the culture of exercise has improved within the department over the past 5 years causing a positive change in overall health and well-being. For example, a member explained that "I know that exercise is undeniably important and something that should be done" (Participant \#1, interview with author, June 2018). And another member stated that "staying fit has the potential to save your own life or the lives of others, and you must have a base level of strength and fitness in order to do the job" (Participant \#14, interview with author July 2018). One member stated that 
"overall and with the introduction of the $02 \mathrm{X}$ program the culture of the fire department has shifted and become more aware of the importance of regular exercise" (Participant \#5, interview with author, June 2018).

However, despite the improvements, one common theme among the participants was that there are still issues that cause them to avoid exercising at the fire station. For instance, a member explained that "I do not typically exercise at the station because I am afraid of an interruption during the workout" (Participant, 8, 2018). Another member noted that "depending on the shift that day there may not be enough time if the companies get a couple working fires, especially the willingness to exercise will be lost! (Participant \#10, interview with author, June 2018).

Another member explained that:

"There is the potential for members to become lazy at the fire station as that may be the only free time they have to escape from the rigors of everyday life. Also, some members may be worried that they will be up throughout the night responding to incidents, therefore, they want to conserve their energy and rest during the day" (Participant \#10, interview with author, June 2018).

\subsection{Sleep-Related Questions}

One of the most common themes in response to the sleep-related questions was that it was often extremely challenging to get any significant amount of rest due to interruptions during the night.

One of the participants explained that:

"Sleep was the one thing that is terrible and even though I can get approximately 6 hours of sleep during a shift the sleep is often interrupted several times due to incident responses and then the department radio is constantly going that makes it hard to sleep" (Participant \#17, interview with author, July 2018).

Another member noted that:

"Most members try to get sleep whenever they can and often take several naps over the course of a shift. Also, in the day following a shift, I will get a little extra rest in order to recover from the day prior" (Participant \#14, interview with author, July 2018).

\subsection{Obesity Question}

We found that most members believed obesity was still present in the department today but was more significant issue earlier in their careers (for most this was about 10 years ago).

For example, two participants stated that:

"I have seen a marked difference in the membership as the members new to the job are in better shape and weigh less than past generations" (Participant \#1, interview with author, June 2018). 
"In fact, I believe the fire department may have a lower rate of obesity than the general population" (Participant \#12, interview with author, July 2018).

However, two members highlighted some of the reasons they believed obesity was prevalent in the department:

"Many members unconsciously eat more while working at the firehouse because more food is readily available. Some members never realize that the ways they conduct themselves at the firehouse are ultimately leading to their weight gain" (Participant \#15, interview with author, July 2018).

"I have a member that works at my fire station that should not allowed to work at a fire station. He does work on a busy company that always gets the job done, but if he went into a collapsed basement, we might lose two members trying to remove him from the basement due to them being out of shape. I think department $X$ is lacking some type of physical fitness standard that follows each member throughout the entirety of their career. One of the common lines I get from other members is oh that guy is a little overweight, but he is a hell of a fireman" (Participant \#17, interview with author, July 2018).

\subsection{Department Resources Regarding Health and Wellness}

In response to the department resources questions, one of the key themes that emerged was that the overall health has improved dramatically over the past five years due in large part to the creation of the SHWD, and the initiation of the O2X program. However, despite the strides the department has made there are still several issues the members believe need to be addressed.

"The department provided very little if any information for the membership on health and wellness and the department used to be very reactive in trying to implement changes after something happened to a member. Now the department is more proactive with all of the programs and new equipment it has introduced into the department" (Participant \#1, interview with author, July 2018).

"The department has done a great job recently in implementing programs like $02 \mathrm{X}$ but the needs to follow up with holding the members accountable for continuing to eat healthy and exercise" (Participant \#14, interview with author, July 2018).

"Each member should have to prove themselves at least once a year via some type of physical fitness assessment test. There needs to be a more stringent method of keeping track of each member's job capabilities throughout their career" (Participant \#17, interview with author, July 2018).

\subsection{Potential Solutions}

After proposing the idea of instituting both a scaled weight requirement and a regular fitness assessment the majority of responses we received were mixed on the idea of weight requirement while most were in favor of a fitness test.

For instance, two members explained that: 
"Having a weight requirement and annual fitness assessment would absolutely be beneficial for the department and if they do not at some point mandate these things the fire department is doomed for failure. As of right now, we have zero standards for fitness" (Participant \#7, interview with author, June 2018).

"A weight requirement would not be beneficial because every member both large and small has a role in the fire department and placing a weight restriction may limit the department in its overall physical capabilities. Big people have their uses with just brute strength that other members do not" (Participant \#3, interview with author, June 2018).

We also proposed the idea of an annual fitness assessment would not only serve to ensure each member is capable of completing their duties but that each member is in the proper health.

"If members knew there was something they had to pass like a fitness assessment in order to stay on the job or be sanctioned they would be motivated to get in shape" (Participant \#10, interview with author, July 2018).

"A regular fitness assessment would force people to be accountable for themselves. It would allow for the department to ensure that every member is functionally capable of performing the tasks of a firefighter. Being in an unfit state in the fire service can pose a risk to not only yourself, but the other members of your group and the people you may

need to save" (Participant \#14, interview with author, July 2018).

\section{Phase li Results}

Phase II of the study corroborated in a larger sample what participants stated in Phase I and reinforced the notion that diets, ability to exercise, and sleep are affected by time spent in the firehouse and concomitant exposure to cultural influences and structural constraints.

\subsection{Sample characteristics}

Demographic data are shown for the total Phase II sample in Tables 2 and 3. The majority of the participants held the rank of firefighters (45\%) and lieutenants (26\%). The mean age of participants was 47 , and ages ranged from 30-64. The mean for total years served in the fire department was 19.5 , and years ranged from $0.75-39$.

The average BMI for the sample was $29.30(n=99)$ while 49 members ( $50 \%$ of the sample) were classified as overweight and 40 members ( $40 \%$ of the sample) were categorized as obese and of that sample $6 \%$ of the participants could be classified as class 2 obese. The BMI data indicates that obesity rates for this sample are in line with national population averages and lower than obesity rates found in the fire service overall. However, since this voluntary sample represents only $9 \%$ of the total department membership, it is possible that these numbers underestimate the actual obesity rate in the broader 
department. Furthermore, it is important to note that $90 \%$ of the sample is still classified as either overweight or obese, underscoring the need to better understand contributing factors in this department.

Table. 2 Demographics for the participants from Phase II of the study

\begin{tabular}{|c|c|c|c|c|c|}
\hline Demographic Questions & & & Response & & \\
\hline Education Level & $\begin{array}{c}\text { High } \\
\text { School } \\
(20 \%) \\
\end{array}$ & $\begin{array}{c}\text { Some college credit, no } \\
\text { degree } \\
(40 \%) \\
\end{array}$ & $\begin{array}{c}\text { Associate } \\
\text { Degree } \\
(9 \%) \\
\end{array}$ & $\begin{array}{c}\text { Bachelor's } \\
\text { Degree } \\
(23 \%) \\
\end{array}$ & $\begin{array}{c}\text { Master's } \\
\text { Degree } \\
(8 \%) \\
\end{array}$ \\
\hline Rank & $\begin{array}{c}\text { Firefighter } \\
\text { (45\%) }\end{array}$ & $\begin{array}{l}\text { Lieutenant } \\
\qquad(26 \%)\end{array}$ & $\begin{array}{l}\text { Captain } \\
\text { (14\%) }\end{array}$ & $\begin{array}{c}\text { District Chief } \\
(11 \%)\end{array}$ & $\begin{array}{c}\text { Deputy Chief } \\
(4 \%)\end{array}$ \\
\hline Average age of participants & & $\mathrm{Re}$ & $\begin{array}{l}\text { e: } 30-64 \text { yrs. } \\
\text { age: } 47 \text { yrs. }\end{array}$ & & \\
\hline Total years served & & Ran & $\begin{array}{l}0.75-39 \text { yrs. } \\
\text { ge: } 19.5 \text { yrs. }\end{array}$ & & \\
\hline $\begin{array}{c}\text { Years spent at current } \\
\text { station }\end{array}$ & & & $\begin{array}{l}\text { e: } 0-29 \text { yrs. } \\
\text { ge: } 5.5 \text { yrs. }\end{array}$ & & \\
\hline $\begin{array}{c}\text { Number of other stations } \\
\text { assigned }\end{array}$ & & & $\begin{array}{l}\text { ge: } 0-18 \\
\text { erage: } 3\end{array}$ & & \\
\hline
\end{tabular}




\begin{tabular}{cc}
\hline Demographic Questions & Response \\
\hline Approximate height & Range: $5^{\prime} 4^{\prime \prime}-6^{\prime} 5^{\prime \prime}$ \\
& Average: $5^{\prime \prime} 9^{\prime \prime}$ \\
\hline Approximate weight & Range: $151-285 \mathrm{lbs}$. \\
& Average: $210.71 \mathrm{lbs}$. \\
\hline BMI & Range: $22.29-37.97$ \\
& Average: $29.30^{*}$ \\
\hline BMI & Range: $18.5-<25$ \\
& Total participants:10 \\
\hline BMI & Range: $25-<30$ \\
& Total participants:49 \\
\hline BMI & Range: $30-<35$ \\
& Total participants:34 \\
\hline BMI & Range: $35-<39$ \\
& Total participants: 6 \\
\hline
\end{tabular}

Table. 3 Participant height, weight, and BMI.

*Normal BMI ranges from $18.5-<25$ (normal), 25 - < 30 (overweight), 30 - <35 (class 1 obese), and <35-39 (class 2 obese moderate risk).

\subsection{Phase Il key variables}

Table 4.summarizes key issues surrounding diet, exercise, and sleep, and highlights things such as obesity, potential solutions, and job performance as it relates to overall health. In general, the participants ( $47 \%$ of the sample) indicated that their diets suffered while working in the firehouse and what contributed most to their unhealthy eating habits were periods of boredom, abundance of desserts, and large portion sizes; all of which are products of the fire department culture and how it is structured.

The majority of the participants indicated that they exercised regularly each week with $34 \%$ stating they exercise at least $1-3$ hours per week, $24 \%$ stating they exercise between 3-6 hours per week, and another $24 \%$ stating they exercise more than 6 hours per week. However, only $51 \%$ of members stated they only exercised 1 hour or less per week at the fire department, which indicates that conditions at the fire station are not necessarily conducive for exercising properly. Additionally, the participants ( $78 \%$ of the sample) indicated that no more than $20 \%$ of the entire membership exercised on a regular basis. The respondents explained that worrying about a potential interruption during the workout and having trouble "getting started" with exercise were the two most significant factors preventing them from exercising in the firehouse.

The majority of the members ( $67 \%$ of the sample) agreed that firefighters could be considered athletes. When asked if they felt that being fit and healthy was imperative to save their life and the lives of others, 
almost all respondents ( $98 \%$ of the sample) agreed with this concept.

Interestingly, as seen in Figure 4, 62\% of the participants agreed with the idea of a fitness requirement but only $34 \%$ agreed with a weight requirement. It was mentioned several times by respondents during Phase I that a weight requirement would be too hard to manage and may penalize members who were overweight. Therefore, it is possible that members have an easier time making a correlation with exercising and job functionality versus diet and job functionality as regular exercise may provide them with tangible results that can be felt and seen more rapidly than dietary changes.

Regarding sleep, the majority of the members (60\% of the sample) get between 3-6 hours of sleep per shift, with almost equal percentages of members ( $20 \%$ of the sample for both variables) either getting more or less sleep. One possible explanation for the variations in sleep would be the location where they are stationed as the busier stations respond to incidents more frequently and slower stations may only receive an incident call once or twice during the entire shift. In terms of what they felt were the greatest contributing factors leading to their lack of sleep during a shift, we found that the majority of respondents felt that the anticipation of interruptions was the most significant factor affecting their sleep, followed by actually responding to calls.

When asked whether or not obesity was prevalent in the department, just over half of respondents (54\% of the sample) agreed obesity was prevalent in department while several ( $30 \%$ of the sample) were uncertain about this question (Figure 6).

When asked whether it is the individual or the fire service who is responsible for the health and wellness of the members, over $83 \%$ of the sample believed it is the responsibility of the individual.

Despite a large percentage of the members indicating that their diets needed improvement and being categorized as overweight, most of the participants rated their overall health between 7 or 8 with (73\% of the sample) on a 10 point scale in which 10 represented excellent health.

\section{Table 4. Phase II key variables}




\begin{tabular}{|c|c|c|c|c|c|}
\hline \multirow[t]{2}{*}{ Question } & \multirow[b]{2}{*}{$\begin{array}{c}\text { I have a very healthy } \\
\text { diet }\end{array}$} & \multirow[b]{2}{*}{$\begin{array}{l}\text { It's normal I stick to } \\
\text { the food pyramid } \\
(32 \%)\end{array}$} & \multicolumn{3}{|c|}{ Response } \\
\hline & & & $\begin{array}{l}\text { My diet needs } \\
\text { some } \\
\text { improvement } \\
(50 \%)\end{array}$ & $\begin{array}{l}\text { My diet is } \\
\text { unhealthy } \\
\text { most of } \\
\text { the time } \\
(3 \%)\end{array}$ & $\begin{array}{l}\text { My diet is } \\
\text { unhealthy all } \\
\text { of the time } \\
(1 \%)\end{array}$ \\
\hline $\begin{array}{l}\text { Diet is better or worse at the } \\
\text { firehouse }\end{array}$ & $\begin{array}{l}\text { My diet is better } \\
\text { when I am at the } \\
\text { firehouse } \\
(5 \%)\end{array}$ & $\begin{array}{l}\text { My diet is worse when I } \\
\text { the firehouse } \\
(46 \%)\end{array}$ & $\begin{array}{r}\text { My die } \\
\text { same re } \\
\text { of whe } \\
\text { (40 }\end{array}$ & $\begin{array}{l}t \text { is the } \\
\text { gardless } \\
\text { re I am } \\
\% \text { ) }\end{array}$ & \\
\hline $\begin{array}{l}\text { Portions served in the } \\
\text { firehouse are too large }\end{array}$ & $\begin{array}{l}\text { Strongly agree } \\
\qquad(29 \%)\end{array}$ & $\begin{array}{l}\text { Agree } \\
(42 \%)\end{array}$ & $\begin{array}{l}\text { Undecided } \\
\qquad(15 \%)\end{array}$ & $\begin{array}{l}\text { Disagree } \\
(13 \%)\end{array}$ & $\begin{array}{c}\text { Strongly } \\
\text { disagree } \\
(1 \%)\end{array}$ \\
\hline $\begin{array}{l}\text { Two factors that contribute } \\
\text { the most to unhealthy } \\
\text { eating habits }\end{array}$ & $\begin{array}{l}\text { Boredom } \\
(31 \%)\end{array}$ & $\begin{array}{c}\text { Presence or } \\
\text { abundance of } \\
\text { desserts } \\
(49 \%)\end{array}$ & $\begin{array}{l}\text { Large portion } \\
\text { sizes } \\
\qquad(15 \%)\end{array}$ & $\begin{array}{l}\text { Other } \\
(5 \%)\end{array}$ & \\
\hline Hours per week & $\begin{array}{l}\text { I do not exercise at all } \\
\qquad(9 \%)\end{array}$ & $\begin{array}{c}<1 \text { hour } \\
(8 \%)\end{array}$ & $\begin{array}{c}1-3 \text { hours } \\
\text { (34\%) }\end{array}$ & $\begin{array}{c}\text { 3-6 hours } \\
(24 \%)\end{array}$ & $\begin{array}{c}\text { More than } 6 \\
\text { hours } \\
(24 \%) \\
\end{array}$ \\
\hline $\begin{array}{l}\text { Hours per week exercise } \\
\text { at the fire station }\end{array}$ & $\begin{array}{l}\text { I do not exercise at all } \\
\qquad(28 \%) \\
\end{array}$ & $\begin{array}{r}<1 \text { hour } \\
(23 \%) \\
\end{array}$ & $\begin{array}{c}1-3 \text { hours } \\
(45 \%) \\
\end{array}$ & $\begin{array}{c}\text { 3-6 hours } \\
(4 \%) \\
\end{array}$ & \\
\hline $\begin{array}{l}\text { Percentage of members you } \\
\text { would say exercise regularly }\end{array}$ & $\begin{array}{r}0-10 \% \\
(21 \%) \\
\end{array}$ & $\begin{array}{l}10-20 \% \\
(57 \%) \\
\end{array}$ & $\begin{array}{l}20-30 \% \\
(14 \%) \\
\end{array}$ & $\begin{array}{r}30-40 \% \\
(7 \%) \\
\end{array}$ & \\
\hline $\begin{array}{l}\text { Two factors that most } \\
\text { interfere with or prevent } \\
\text { exercise (variable 1) }\end{array}$ & $\begin{array}{l}\text { Worrying about } \\
\text { potential interruption } \\
\qquad(53 \%)\end{array}$ & $\begin{array}{l}\text { Feeling a need to } \\
\text { conserve energy } \\
\text { for potential } \\
\text { response to a fire } \\
(8 \%)\end{array}$ & $\begin{array}{c}\text { Having } \\
\text { trouble } \\
\text { "getting } \\
\text { started" with } \\
\text { exercise } \\
(17 \%) \\
\end{array}$ & $\begin{array}{l}\text { None of the above } \\
\qquad(17 \%)\end{array}$ & $\begin{array}{l}\text { Other } \\
(4 \%)\end{array}$ \\
\hline $\begin{array}{l}\text { Two factors that most } \\
\text { interfere with or prevent } \\
\text { exercise (variable 2) }\end{array}$ & $\begin{array}{c}\text { Feeling a need to } \\
\text { conserve energy for } \\
\text { potential response to } \\
\text { a fire } \\
(31 \%)\end{array}$ & $\begin{array}{l}\text { Having trouble } \\
\text { "getting started" } \\
\text { with exercise } \\
(65 \%)\end{array}$ & $\begin{array}{l}\text { Other } \\
(4 \%)\end{array}$ & & \\
\hline Firefighters are athletes & $\begin{array}{l}\text { Strongly agree } \\
\qquad(21 \%)\end{array}$ & $\begin{array}{l}\text { Agree } \\
(46 \%)\end{array}$ & $\begin{array}{l}\text { Undecided } \\
\qquad(17 \%)\end{array}$ & $\begin{array}{l}\text { Disagree } \\
(13 \%)\end{array}$ & $\begin{array}{l}\text { Strongly } \\
\text { disagree }\end{array}$ \\
\hline
\end{tabular}

$(2 \%)$

\begin{tabular}{lccc}
\hline $\begin{array}{l}\text { Staying fit and healthy has } \\
\text { the potential to save my life }\end{array}$ & Strongly agree & Agree & Undecid \\
and the lives of others & $(70 \%)$ & $(28 \%)$ & $(2 \%)$
\end{tabular}

\begin{tabular}{|c|c|c|c|}
\hline $\begin{array}{l}\text { How many hours of sleep } \\
\text { do you receive during a } \\
\text { regular shift }\end{array}$ & $\begin{array}{c}1-3 \text { hours } \\
(20 \%)\end{array}$ & $\begin{array}{c}\text { 3-6 hours } \\
(60 \%)\end{array}$ & $\begin{array}{c}\text { More than } 6 \\
\text { hours }\end{array}$ \\
\hline
\end{tabular}

(20\%)

Two factors that have the greatest impact on your
Lack of comfort Responding to

calls

Page 13/21 
$(7 \%)$

\begin{tabular}{|c|c|c|c|c|c|}
\hline $\begin{array}{l}\text { Two factors that have the } \\
\text { greatest impact on your } \\
\text { ability to sleep at the fire } \\
\text { station (variable 2) }\end{array}$ & $\begin{array}{l}\text { Responding to calls } \\
\qquad(8 \%)\end{array}$ & $\begin{array}{l}\text { Anticipation of } \\
\text { interruptions } \\
(85 \%) \\
\end{array}$ & $\begin{array}{c}\text { None of the } \\
\text { above } \\
(2 \%)\end{array}$ & $\begin{array}{l}\text { Other } \\
(5 \%)\end{array}$ & \\
\hline $\begin{array}{l}\text { I feel as though obesity is } \\
\text { prevalent in the department }\end{array}$ & Strongly agree & Agree & Undecided & Disagree & $\begin{array}{l}\text { Strongly } \\
\text { disagree }\end{array}$ \\
\hline
\end{tabular}

\begin{tabular}{lcccc}
\hline \multicolumn{2}{c}{ Question } & & Response \\
\hline $\begin{array}{l}\text { Having regular fitness assessments and/or } \\
\text { required weekly exercise would foster a } \\
\text { healthier overall environment }\end{array}$ & $\begin{array}{c}\text { Strongly } \\
\text { agree }\end{array}$ & Agree & Undecided & Strongly \\
disagree
\end{tabular}

\begin{tabular}{lccccc}
\hline $\begin{array}{l}\text { I believe that having a weight requirement } \\
\text { would be beneficial }\end{array}$ & $\begin{array}{c}\text { Strongly } \\
\text { agree }\end{array}$ & Agree & Undecided & Strongly disagree \\
& $(8 \%)$ & $(26 \%)$ & $(31 \%)$ & Disagree & $(9 \%)$
\end{tabular}

Health and well-being is the responsibility Average:

of the fire service

Average:

Health and well-being is the responsibility

of the individual

\begin{tabular}{|c|c|c|c|c|c|c|c|c|c|}
\hline \multirow[t]{2}{*}{ Rate your overall health } & 0 & 3 & 4 & 5 & 6 & 7 & 8 & 9 & 10 \\
\hline & $(1 \%)$ & $(1 \%)$ & $(2 \%)$ & $(9 \%)$ & $(11 \%)$ & (28\%) & (34\%) & (5\%) & $(8 \%)$ \\
\hline
\end{tabular}

\section{Discussion}

In this sample, we found that the majority of the respondents in both phases of the study indicated that their diets suffered significantly while working at the firehouse due to the large portion sizes, the abundance of desserts, and periods of boredom while working a shift. Regardless of a person's health status, it has been found that consuming meals with larger portions increases the risk of becoming overweight or obese as the average energy intake is greater than the daily amount needed for each member (16). These findings contribute to other research that highlights the issues surrounding the 
culture of food in the fire service and pinpoints what is impeding the members' ability to maintain a healthy diet (17).

We found that the majority of respondents avoided exercising during a shift due to potential interruptions and that they had a hard time "getting started" with exercise. The irregularity in the frequency of exercise for members is problematic as the World Health Organization (WHO) recommends that adults ages 1864 minimally should attain at least 150 minutes of exercise per week as it can reduce cancer and cardiovascular mortality risk $(18,19)$. It is widely understood that engaging in regular physical fitness can lower blood pressure and reduce the risk of becoming hypertensive (20). Additionally, recent research has shown that those in proper cardiorespiratory fitness condition are $45 \%$ less likely to succumb to cancer mortality versus those who are not, which is significant for firefighters as they are already at a disadvantage in terms of various types of cancers and being exposed to harmful carcinogens on a regular basis (21).

The department has attempted to increase physical activity for the members by partnering with $02 X$ which is an organization that specializes in diet, exercise, sleep, recovery, and mental health, specifically for tactical athletes such as members of fire, police, and ems entities. Together, $02 X$ and the $X$ Fire Department have implemented an exercise program, which a recent study has shown has benefited the department since its inception in 2016. In particular, the 16-week program was able to increase the overall levels of physical fitness for the members who participated (22). However, the program is not mandatory nor are the members allotted specific time to exercise during a shift leaving them to struggle with the concerns they expressed in both phases of the study regarding exercise. The findings in Phase II regarding hypothetical solutions are significant as the majority of the participants were in favor of a mandated fitness assessment and such data can then be used by department officials to institute a real fundamental change.

The findings regarding sleep build on existing research that shows getting the proper amount of sleep during a shift is extremely challenging due to interruptions from incident responses throughout the night. Recent research has shown that interrupted sleep is associated with obesity risk, therefore, the 24-hour work schedule that many fire departments adhere to could be contributing to levels of overweight and obesity (23).

The BMI data in Phase II indicates that many participants were either overweight or obese, which becomes problematic because being overweight puts people, especially firefighters, at an increased risk for many diseases such as diabetes, cardiovascular disease, colon cancer $(24,25)$. Furthermore, as shown in Table 4., many of the respondents ( $46 \%$ of the sample) were either undecided or disagreed with the idea that obesity was prevalent in the department while many of the respondents ( $54 \%$ of the sample) believed that obesity was prevalent. This finding is consistent with previous literature indicating that overweight and obese firefighters can misjudge their weight category and their perception of being overweight or obese (26). 
Furthermore, recent research has shown that the way in which firefighters view health-related factors such as obesity, cardiovascular disease, and their overall health is due is associated with the intense physical nature of the job as members use their performance abilities on the job as a gauge for their health (27). Firefighters are in a physically demanding job, therefore, if they can perform their job effectively they may feel as though they are in proper physical shape regardless of their actual condition (28). Therefore, it is important for departments to insert preventative measures like regular fitness assessments, dietary, and sleep guidance in order to ensure the members are at optimum levels of overall health.

Our findings regarding the responsibility of health in the fire service indicate that despite all of the barriers members encounter regarding diet, exercise, sleep, and overall health, the majority of respondents still believe that being in good health is a personal choice. Obesity, fitness, and other aspects of lifestyle are often considered to be matters of personal choice in societal and public health discourses, however, being able to maintain healthy lifestyles is not always in the control of the individual, especially in the fire service $(29,30)$. Furthermore, it is interesting to learn that despite the respondents acknowledging that the structure of the fire department is negatively impacting their ability to eat, sleep, and exercise properly, the majority still believe each individual is ultimately responsible for controlling these aspects.

Ultimately, social and environmental factors do affect people's weight and physical activity, therefore, we believe that what is negatively impacting diet, exercise, and sleep stems from the overall structure and environment of the fire service which has assisted in creating a certain culture that is affecting the behaviors of the members (31). We propose that as new members join the department, they are influenced by a version of "biosocial inheritance", which is the idea that learned behaviors and cultural attitudes that may negatively impact health can be passed on from generation to generation (32). Especially in an industry such as the fire department, which is bound by many deep-rooted traditions, cultural norms around lifestyle can perpetuate, as new members follow the traditions of the fire service, and as they join the ranks they become immersed in behaviors of past generations $(33,34)$. Furthermore, research has shown that when people have social connections with others who are obese they are at a greater risk of becoming obese themselves due to shared behaviors $(35,36)$.

\section{Limitations}

Our study has limitations, including a relatively small sample size for both phases of the study. Additionally, due to the study being voluntary it is unclear if the participants that did choose to participate, especially in Phase I, were more concerned with maintaining a proper diet and exercise regimen versus those that did not participate.

\section{Conclusion}

Despite these limitations, the research we conducted is significant as it helps to highlight several issues surrounding diet, exercise, and sleep from the voice of the members rather than an outside perspective. The study reveals that the structure and environment of the fire department is negatively impacting the 
members' diet, exercise, and sleep habits, which in turn puts respondents at risk for becoming either overweight or obese. The data gathered from the study should serve as a guideline for implementing policy changes within the fire service to mitigate and prevent these issues from occurring in the future. Ultimately, we hope that this study can serve as a useful guideline for not only the X Fire Department but other departments nationally. However, further research should be conducted with other departments to determine the most pervasive issues impacting ability to eat, sleep, and exercise more broadly within the fire service.

\section{Declarations}

\section{Ethics approval and consent to participate}

Initial permission to conduct the research study was obtained by the members of the X Fire Department. The members that chose to participate in the study were provided with full disclosure of the nature and scope of the research, and no data was collected unless informed consent was verbally granted. The members were told they were free at any point to remove themselves from the study. The study did not contain any identifying markers whatsoever. All of the participants and the information collected from the participants remained anonymous. Additionally, the name of the department was omitted to further ensure the anonymity of all participants.

\section{Consent for publication}

Please see explanation within the methods section.

\section{Availability of data and materials}

The datasets used and/or analyzed during the current study are available from the corresponding author on reasonable request.

\section{Competing interests}

The authors declare that they have no competing interests.

\section{Funding}

The authors declare that no funding was used to perform this research study.

\section{Author's contributions}


MB conceptualized the research study, collected and analyzed data, and wrote the manuscript. ES oversaw and contributed to the design of the study, assisted with data analysis, and contributed to writing and editing the manuscript.

\section{Acknowledgements}

The authors would like to thank the members of the X Fire Department for their participation in the study and their support throughout the entire process. Additionally, we would like to thank Dr. Sara Jahnke for her suggestions and support throughout the entirety of the project.

\section{References}

${ }^{1}$ NFPA 1582. (2017, November 18). Retrieved July 03, 2019, from https://www.nfpa.org/codes-andstandards/all-codes-and-standards/list-of-codes-and-standards/detail?code $=1582$

${ }^{2}$ Wilkinson, M. L., Brown, A. L., Poston, W. S., Haddock, C. K., Jahnke, S. A., \& Day, R. S. (2014). Physician weight recommendations for overweight and obese firefighters, United States, 2011-2012. Preventing chronic disease, 11, E116. doi:10.5888/pcd11.140091

${ }^{3}$ Adult Obesity Facts | Overweight \& Obesity | CDC. (n.d.). Retrieved July 26, 2019, from https://www.cdc.gov/obesity/data/adult.html

${ }^{4}$ Brown, A. L., Poston, W. S., Jahnke, S. A., Haddock, C. K., Luo, S., Delclos, G. L., \& Day, R. S. (2016). Weight loss advice and prospective weight change among overweight firefighters. International Journal of Occupational and Environmental Health, 22(3), 233-239. doi:10.1080/10773525.2016.1207045

${ }^{5}$ Banes, C. J. (2014). Firefighters' Cardiovascular Risk Behaviors: Effective Interventions and Cultural Congruence. Workplace Health \& Safety, 62(1), 27-34. doi:3928/21650799-20131220-05

${ }^{6}$ Thyfault, J. P. \& Booth, F. W. (2011). Lack of regular physical exercise or too much inactivity. Current Opinion in Clinical Nutrition and Metabolic Care, 14(4), 374-378. doi: 10.1097/MC0.0b013e3283468e69.

${ }^{7}$ Crockett, A. C., Myhre, S. K., \& Rokke, P. D. (2015). Boredom proneness and emotion regulation predict emotional eating. Journal of Health Psychology, 20(5), 670-680. doi:10.1177/1359105315573439

${ }^{8}$ Bonnell, E., Huggins, C., Mccaffrey, T., Palermo, C., \& Bonham, M. (2017). Influences on Dietary Choices during Day versus Night Shift in Shift Workers: A Mixed Methods Study. Nutrients, 9(3), 193. doi:10.3390/nu9030193

${ }^{9}$ Haddock, C. K., Poston, W. S., Jahnke, S. A. (n.d.). Addressing the Epidemic of Obesity in the United States Fire Service. Retrieved July 12, 2018, from www.nvfc.org 
${ }^{10}$ Harrington, J. M. (2001). Health effects of shift work and extended hours of work. Occupational and Environmental Medicine, 58(1), 68-72. doi:10.1136/oem.58.1.68

${ }^{11}$ Domínguez, F., Fuster, V., Fernández-Alvira, J. M., Fernández-Friera, L., López-Melgar, B., Blanco-Rojo, R.,... Ordovás, J. M. (2019). Association of Sleep Duration and Quality With Subclinical Atherosclerosis. Journal of the American College of Cardiology, 73(2), 134-144. doi:10.1016/j.jacc.2018.10.060

${ }^{12}$ Hunter, A. L., Shah, A. S., Langrish, J. P., Raftis, J. B., Lucking, A. J., Brittan, M.,... Mills, N. L. (2017). Fire simulation and cardiovascular health in firefighters. Circulation, 135(14), 1284-1295.

doi:10.1161/circulationaha.116.025711

${ }^{13}$ Kales, S. N., Soteriades, E. S., Christoudias, S. G., \& Christiani, D.C. (2003). Firefighters and on-duty deaths from coronary heart disease: A case control study. Environmental Health, 2(1). doi:10.1186/1476$069 x-2-14$

${ }^{14}$ Goheer, A., Bailey, M., Gittelsohn, J., \& Pollack, K. M. (2014). Fighting Fires and Fat: An Intervention to Address Obesity in the Fire Service. Journal of Nutrition Education and Behavior, 46(3), 219-220. doi:10.1016/j.jneb.2013.05.003

${ }^{15}$ Ryan, G. W., \& Bernard, H. R. (2003). Techniques to Identify Themes. Field Methods, 15(1), 85-109. doi: $10.1177 / 1525822 \times 02239569$

${ }^{16}$ Greenwood, J. L., \& Stanford, J. B. (2008). Preventing or Improving Obesity by Addressing Specific Eating Patterns. The Journal of the American Board of Family Medicine, 21(2), 135-140. doi:10.3122/jabfm.2008.02.070034

17 Jahnke, S. A., Poston, W. S., Jitnarin, N., \& Haddock, C. K. (2012). Health concerns of the U.S. fire service: perspectives from the firehouse. American journal of health promotion: AJHP, 27(2), 111-118. doi:10.4278/ajhp.110311-QUAL-109

${ }^{18}$ Physical Activity and Adults. (2015, June 19). Retrieved July 08, 2019, from https://www.who.int/dietphysicalactivity/factsheet_adults/en/

${ }^{19}$ Wen, C. P., Wai, J. P., Tsai, M. K., Yang, Y. C., Cheng, T. Y., Lee, M.,... Wu, X. (2011). Minimum amount of physical activity for reduced mortality and extended life expectancy: A prospective cohort study. The Lancet, 378(9798), 1244-1253. doi:10.1016/s0140-6736(11)60749-6

${ }^{20}$ Cornelissen, V. A., \& Fagard, R. H. (2005). Effects of Endurance Training on Blood Pressure, Blood Pressure-Regulating Mechanisms, and Cardiovascular Risk Factors. Hypertension, 46(4), 667-675. doi:10.1161/01.hyp.0000184225.05629.51

${ }^{21}$ Schmid, D., \& Leitzmann, M. F. (2014). Cardiorespiratory fitness as predictor of cancer mortality: A systematic review and meta-analysis. Annals of Oncology, 26(2), 272-278. doi:10.1093/annonc/mdu250 
22 La Reau, A. C., Urso, M. L., \& Long, B. (2018, October). A Study Published in the Journal of Exercise Physiology (online) Highlights Impact of O2X. Retrieved July 10, 2019, from https://o2x.com/press/study-journal-of-exercise-physiology-oct2018/

${ }^{23}$ Beccuti, G., \& Pannain, S. (2011). Sleep and obesity. Current opinion in clinical nutrition and metabolic care, 14(4), 402-412. doi:10.1097/MC0.0b013e3283479109

${ }^{24}$ Must, A. (1999). The Disease Burden Associated With Overweight and Obesity. Jama, 282(16), 1523. doi:10.1001/jama.282.16.1523

${ }^{25}$ Frezza, E. E., Wachtel, M. S., \& Chiriva-Internati, M. (2006). Influence of obesity on the risk of developing colon cancer. Gut, 55(2), 285-291. doi:10.1136/gut.2005.073163

${ }^{26}$ Baur, D. M., Christophi, C. A., Tsismenakis, A. J., Jahnke, S. A., \& Kales, S. N. (2012). Weight- perception in male career firefighters and its association with cardiovascular risk factors. BMC Public Health, 12(1). doi:10.1186/1471-2458-12-480

27 Kay, B., Lund, M. M., Taylor, P. N., \& Herbold, N. H. (2001). Assessment of Firefighters' Cardiovascular Disease-related Knowledge and Behaviors. Journal of the American Dietetic Association, 101(7), 807809. doi:doi.org/10.1016/S0002-8223(01)00200-0

28 Turner, P. J. F., Siddall, A. G., Stevenson, R. D., Standage, M., \& Bilzon, J. L. J. (2018). Lifestyle behaviours and perceived well-being in different fire service roles. Occupational Medicine, 68(8), 537543. https://doi.org/10.1093/0ccmed/kqy110

${ }^{29}$ Keightley, J., Chur-Hansen, A., Princi, R., \& Wittert, G. A. (2011). Perceptions of obesity in self and others. Obesity Research \& Clinical Practice, 5(4). doi:10.1016/j.orcp.2011.03.013

${ }^{30}$ Mayes, C. (2017). The biopolitics of lifestyle: Foucault, ethics and healthy choices. New York: Routledge, Taylor \& Francis Group.

${ }^{31}$ Poortinga, W. (2006, September 06). Perceptions of the environment, physical activity, and obesity. Retrieved July 08, 2019, from https://www.sciencedirect.com/science/article/pii/S0277953606003

32 Jernigan, Kasey. "Introduction: Biocultural Contributions To The Study Of Health Disparities." Annals of Anthropological Practice: Anthropological Insights on Effective Community-Based Coalition, by Thomas Leatherman, John Wiley \& Sons, 2012, pp. 171-186

${ }^{33}$ Rothmeier, J. (2017, May 26). Challenging Tradition. Retrieved July 21, 2019, from https://www.firerescuemagazine.com/articles/print/volume-12/issue-5/features/challengingtradition.html 
${ }^{34}$ Warren, T. (2019, January 22). Embracing Traditions in the Modern Fire Service. Retrieved July 21, 2019, from https://www.fireengineering.com/articles/2019/01/fire-service-traditions.html

${ }^{35}$ Christakis, N. A., \& Fowler, J. H. (2007). The Spread of Obesity in a Social Network. New England Journal of Medicine, 357(18), 1866-1868. doi:10.1056/nejmc072478

${ }^{36}$ Christakis, N. (2004, July 24). Social networks and collateral health effects. Retrieved July 17, 2019, from https://www.ncbi.nlm.nih.gov/pmc/articles/PMC487721/

\section{Figures}

\section{Obesity is Prevalent in the Department}

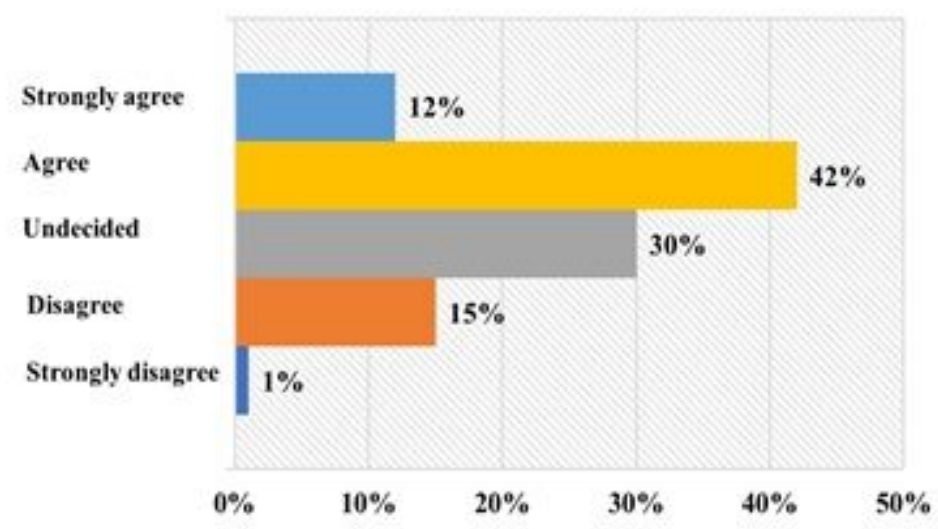

\section{Figure 1}

Members' perceived prevalence of obesity in the department. 